\title{
Extracellular Matrix Plays an Important Role in Stem Cell Biology
}

\section{Yi Wen ${ }^{1,2}$, Sijun $\mathrm{Hu}^{3}$, Junjie $\mathbf{W u}^{1,2 *}$}

${ }^{1}$ State Key Laboratory of Military Stomatology, Xi'an, Shaanxi Province, People's Republic of China

${ }^{2}$ Department of Orthodontics, Fourth Military Medical University, School of Stomatology, Xi'an, Shaanxi Province, People's Republic of China

${ }^{3}$ State Key Laboratory of Cancer Biology and Xijing Hospital of Digestive Diseases, The Fourth Military Medical University, Xi'an, Shaanxi Province, China

Keywords: Extracellular matrix; Stem cell biology; Stem cells; Tissue

\section{Editorial}

In vivo stem cells live in a complex microenvironment called stem cell niche [1-3]. Stem cell niche can affect stem cell behavior and regulate stem cell fate by multiple signals. These signals may be structural, physical, electrical or biochemical. In the human body, the stem cell microenvironment can maintain adult stem cell in a quiescent state. But after the tissue injury, the surrounding microenvironment actively sends out signals to promote self-renewal and differentiation of stem cells to form new tissues. Some factors are significant to their properties in the microenvironment, such as interactions between stem cells, interactions between stem cells and surrounding differentiated cells, interactions between stem cells and adhesion molecules, extracellular matrix, oxygen tension, etc. Extracellular matrix (ECM) is an important component of stem cell niche, which involved in almost all of these signals [4-5]. Cells elaborate their ECM by secreting proteins, which in turn regulate cell behavior and influence the remodeling of ECM [6-7].

There are many kinds of macromolecules in the ECM, which can be generally classified into different main groups: fibrous proteins, including collagen, elastin, fibronectin, and laminin; proteoglycans (PGs), and glycosaminoglycans (GAGs) [8]. Collagen is the most abundant protein in humans, which accounts for more than $30 \%$ of the total protein. It is located in a variety of organs and tissues in the body and it is a frame structure in the ECM, which can be synthesized and secreted by fibroblasts, chondrocytes, osteoblasts and some epithelial cells. It is designed to provide strength and resiliency to tissues, and able to regulate cell adhesion, chemotaxis, and migration, and to guide tissue development [9-10]. Fibronectin (FN) has plenty of functions that ensure the normal function of vertebrate organisms. It is involved in cell adhesion, growth, migration, and differentiation. Cellular fibronectin is assembled into the extracellular matrix, an insoluble network that separates and supports the organs and tissues. FN is involved in many diseases, such as cardiovascular disease and tumor metastasis $[9,11]$. Proteoglycans (PGs) are a major component of the animal ECM. They are involved in binding cations (such as sodium, potassium and calcium) and water, and also regulating the movement of molecules through the matrix [12]. Evidence also shows that they can affect the activity and stability. PGs can interact with growth factors, cytokines and chemokines, and interact with other ECM molecules in the process of different cell functions, which is beneficial to the formation of ECM scaffold [13].

ECM plays an active role in cell life: survival, motility, and communication. ECM not only provides structural scaffold for cells, but also promotes the function of cells and organs. Besides, ECM is of significance in regulating cell function in different ways, such as mechanical stimulation which can change the stiffness of the matrix components, thereby directly affecting cell differentiation [14-18]. Moreover, ECM can regulate the availability and activity of soluble factors by combining its own components with many soluble factors (e.g., BMP). In addition, ECM proteins can interact with cell adhesion molecules, thereby affecting chemical signals and intracellular signals, as well as stem cell differentiation. Thus, ECM affects cell processes, and even gene expression through different stimulus [19]. In addition, it is worth mentioning that, ECM is also involved in cell death process. In fact, programmed cell death, also known as anoikis, is due to a decrease in the interaction between the cells and ECM which is resulting from detachment between cells and ECM [20].

It is demonstrated by Kevin Lynch and Ming Pei [21] that the age-associated changes in proliferation and differentiation ability of mesenchymal stem cell (MSC) and the use of the ECM derived from young cells can rejuvenate old cell. In conclusion, the stiffness of ECM gradually increases with age, collagen and GAG accumulation, as well as the accumulation of other proteins. Their laboratory also showed that young ECM can promote MSC proliferation to a greater extent compared with mature ECM. Therefore, it is concluded that fetal ECM may promote the proliferation of stem cells in a manner similar to how adult ECM can direct MSC differentiation. What is more, Sun Y et al. [22] believed that ECM can maintain the function of MSC under normal circumstances, but aging can negatively affect the formation of ECM. When cultured on the young- ECM, the aged MSC can be rejuvenated.

Han Wang et al. [23] reported how ECM and its interaction with integrin receptors affect embryonic stem cells (ESC) differentiation. A more reasonable understanding of integrin-mediated interactions between cells and ECM and integrin signaling pathways in ESC differentiation may improve the effectiveness and specificity of ESC differentiation in research and clinical applications.

Interestingly, Milos Marinkovic et al. [24] proposed that ECM is tissue-specific. They used bone marrow (BM)-derived and adipose (AD) -derived stromal cells to prepare BM-ECM and AD-ECM which are decellularized to mimic the cellular niche of these tissues. Each ECM can influence the $\mathrm{BM}$, and $\mathrm{AD}$-derived cells proliferation, cell stretch, and direct proliferation on the surface of tissue culture polystyrene (TCP) surface. Also, they found that the effect of proliferation of BMderived MSC is more remarkable than the AD-derived MSC, and vice versa. In addition, BM-ECM and AD-ECM have significant effects on the osteogenic and adipogenic differentiation of MSC respectively, indicating that ECM has tissue specificity. Moreover, each ECM has an ability of affecting cell morphology, regardless of cell origin, and the results further suggested that ECM is tissue-specific.

${ }^{*}$ Corresponding author: Junjie Wu, Department of Orthodontics, School of Stomatology, Fourth Military Medical Univeristy, Xi'an, China, E-mail: wujunjiedds@163.com

Received January 17, 2017; Accepted January 27, 2017; Published May 31 2018

Citation: Wen Y, Hu S, Wu J (2018) Extracellular matrix plays an important role in stem cell biology. J Stem Cell Res Ther: e122

Copyright: (C) 2018 TWen Y, et al. This is an open-access article distributed under the terms of the Creative Commons Attribution License, which permits unrestricted use, distribution, and reproduction in any medium, provided the original author and source are credited. 
ECM has great prospects in the field of tissue regeneration, because it has immune tolerance, thereby it comes about minimal immune rejection in the receptor [25]. Besides, ECM provides a physical and functional environment for cells. Therefore, the purpose of using ECM as scaffold in tissue engineering is to mimic the ECM structure of the target tissues as much as possible. For instance, Ott $\mathrm{HC}$ et al. [26] decellularized lungs and seeded scaffolds with epithelial and endothelial cells to regenerate gas exchange tissue. After transplanted, the ventilation function regenerated lung was restored. With these technologies from laboratory to clinical applications, ECM is bound to create a broad field of medical transplantation tissue engineering. Taking into account the impact of these technologies on the quality of life of patients, the ECM-based regeneration technology needs to be continually reevaluated.

\section{References}

1. Wang C, Tian C, Zhang $Y$ (2016) The Interaction between niche and hematopoietic stem cells. Indian J Hematol Blood Transfus 32: 377-382. [PubMed]

2. Omatsu $Y(2016)$ The niche for hematopoietic stem and progenitor cells in bone marrow. Clin Calcium 26: 671-676. [PubMed]

3. Regalado-Santiago C, Juárez-Aguilar E, Olivares-Hernández JD, Tamariz E (2016) Mimicking neural stem cell niche by biocompatible substrates. Stem Cells Int 2016: 1513285. [PubMed]

4. Gattazzo F, Urciuolo A, Bonaldo P (2014) Extracellular matrix: A dynamic microenvironment for stem cell niche. Biochim Biophys Acta 1840(8): 25062519. [PubMed]

5. Jones DL, Wagers AJ (2008) No place like home: Anatomy and function of the stem cell niche. Nat Rev Mol Cell Biol 9(1): 11-21. [PubMed]

6. Horne JT, Segal TR, Chang S, Jorge S, Segars JH, et al. (2015) Dynamic reciprocity between cells and their microenvironment in reproduction. Biol Reprod 92(1): 25. [PubMed]

7. Kaul H, Ventikos Y (2015) Dynamic reciprocity revisited. J Heor Biol 370: 205208. [PubMed]

8. Heocharis AD, Skandalis SS, Gialeli C, Karamanos NK (2016) Extracellular matrix structure. Adv Drug Deliv Rev 97: 4-27. [PubMed]

9. Rozario T, DeSimone DW (2010) The extracellular matrix in development and morphogenesis: A dynamic view. Dev Biol 341(1): 126-140. [PubMed]

10. Ghazanfari S, Khademhosseini A2, Smit TH3 (2016) Mechanisms of lamellar collagen formation in connective tissues. Biomaterials 97: 74-84. [PubMed]

11. Tsang KY, Cheung MC, Chan D, Cheah KS (2010) The developmental roles of the extracellular matrix: beyond structure to regulation. Cell Tissue Res 339: 93-110. [PubMed]
12. Song $Y$ (2016) Function of membrane-associated proteoglycans in the regulation of satellite cell growth. Adv Exp Med Biol 900: 61-95. [PubMed]

13. Heocharis AD, Skandalis SS, Tzanakakis GN, Karamanos NK (2010) Proteoglycans in health and disease: Novel roles for proteoglycans in malignancy and their pharmacological targeting. FEBS J 277(19): 3904-3923. [PubMed]

14. Hoshiba T, Chen G, Endo C, Maruyama H, Wakui M, et al. (2016) Decellularized extracellular matrix as an in vitro model to study the comprehensive roles of the ECM in stem cell differentiation. Stem Cells Int 2016: 6397820.

15. Lo CM, Wang HB, Dembo M, Wang YL (2000) Cell movement is guided by the rigidity of the substrate. Biophys J 79(1): 144-152. [PubMed]

16. Engler AJ, Sen S, Sweeney HL, Discher DE (2006) Matrix elasticity directs stem cell lineage specification. Cell 126: 677-689. [PubMed]

17. Paszek MJ, Zahir N, Johnson KR, Lakins JN, Rozenberg GI, et al. (2005) Tensional homeostasis and the malignant phenotype. Cancer Cell 8(3): 241 254. [PubMed]

18. Engler AJ, Griffin MA, Sen S, Bönnemann CG, Sweeney HL, et al. (2004) Myotubes differentiate optimally on substrates with tissue-like stiffness pathological implications for soi or stiff microenvironments. J Cell Biol 166(6) 877-887. [PubMed]

19. Kadler KE, Baldock C, Bella J, Boot-Handford RP (2007) Collagens at a glance. J Cell Sci 120: 1955-1958. [PubMed]

20. Nagaprashantha LD, Vatsyayan R, Lelsani PC, Awasthi S, Singhal SS (2011) The sensors and regulators of cell-matrix surveillance in anoikis resistance of tumors. Int J Cancer 128: 743-752. [PubMed]

21. Lynch K, Pei M (2014) Age associated communication between cells and matrix: A potential impact on stem cell-based tissue regeneration strategies. Organogenesis 10(3): 289-298. [PubMed]

22. Sun Y, Li W, Lu Z, Chen R, Ling J, et al. (2011) Rescuing replication and osteogenesis of aged mesenchymal stem cells by exposure to a young extracellular matrix. FASEB J 25(5):1474-1485. [PubMed]

23. Wang H, Luo X, Leighton J (2015) Extracellular matrix and integrins in embryonic stem cell differentiation. Biochem Insights 8: 15-21. [PubMed]

24. Marinkovic M, Block TJ, Rakian R, Li Q, Wang E, et al. (2016) One size does not fit all: Developing a ceOO-specific niche for in vitro study of cell behavior. Matrix Biol 52-54: 426-441. [PubMed]

25. da Anunciação ARA, Mess AM, Orechio D, Aguiar BA, Favaron PO, et al. (2016) Extracellular matrix in epitheliochorial, endotheliochorial and haemochorial placentation and its potential application for regenerative medicine. Reprod Domest Anim 52(1): 3-15. [PubMed]

26. Ott HC, Clippinger B, Conrad C, Schuetz C, Pomerantseva I, et al. (2010) Regeneration and orthotopic transplantation of a bioartificial lung. Nat Med 16 927-933. 